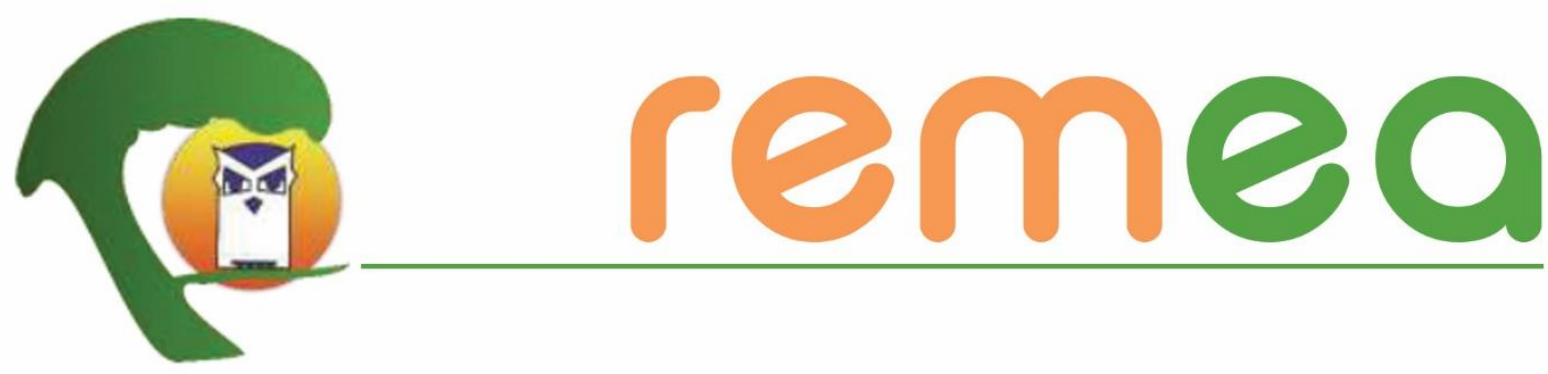

\title{
Percepções socioambientais de estudantes do Ensino Fundamental sobre o Rio Macaco em Palmeira das Missões/RS
}

\author{
Jeferson Rosa Soares ${ }^{1}$ \\ Universidade Federal do Rio Grande do Sul \\ ORCID http://orcid.org/0000-0002-8654-6316 \\ Roselane Zordan Costella ${ }^{2}$ \\ Universidade Federal do Rio Grande do Sul \\ ORCID https://orcid.org/0000-0002-1297-1352 \\ José Vicente Lima Robaina ${ }^{3}$ \\ Universidade Federal do Rio Grande do Sul \\ ORCID https://orcid.org/0000-0002-4604-3597
}

Resumo: O Rio Macaco em Palmeira das Missões/RS vem sofrendo diversos impactos ocasionados pela ação antrópica. Neste sentido, este artigo tem como finalidade avaliar as percepções socioambientais de alunos do 5 ㅇ ao 9을 ano de três escolas municipais de ensino fundamental sobre a temática microbacia do Rio Macaco, por meio de um questionário semiestruturado aplicado em diferentes regiões do município. Para a análise dos resultados foi utilizada a metodologia qualitativa de Análise de Conteúdo. Os resultados demonstram que o conhecimento dos alunos sobre a temática é inconsistente e inadequado, demonstrando a importância de uma

\footnotetext{
${ }^{1}$ Doutorando em Educação em Ciências-UFRGS, Mestre em Educação Ambiental-FURG, Tecnólogo em Gestão Ambiental-UNOPAR, Especialista em Educação em Ciências-UNIPAMPA. Porto Alegre/RS. E-mail: josoares77@gmail.com

${ }^{2}$ Licenciatura em Geografia, Mestrado e Doutorado na linha de pesquisa em ensino de Geografia pela Universidade Federal do Rio Grande do Sul. Cursou pós-doutorado no Programa de Pós-Graduação em Geografia (UFRGS) estendido na Universidad de Valencia (Espanha). Tem vasta experiência na Educação Básica e no Ensino Superior como professora e assessora de ensino. Professora Associada, classe D, nível 01 da Faculdade de Educação - FACED/UFRGS no Departamento de Ensino e Currículo, no Núcleo de Estudos em Educação e Geografia (NEEGEO). Professora no Programa de Pós-Graduação em Geografia (POSGEA/UFRGS). Coordenou a Coordenadoria das Licenciaturas da UFRGS/COORLICEN - gestão 2015 - 2017. Porto Alegre/RS. Email: professoracostella@gmail.com

3 Doutor em Educação, UNISINOS (2007), Mestre em Educação, UFRGS (1996), Graduação em Licenciatura Plena em Química PUCRS (1985), Graduação em Licenciatura Curta em Ciências PUCRS (1982) e Professor Adjunto do Campus Porto Alegre, Departamento de Ensino e Currículo (DEC), da Faculdade de Educação (FACED), do curso de Educação do Campo: Licenciatura em Ciências da Natureza, UFRGS. Professor do PPG Educação em Ciências: Química da Vida e Saúde, UFRGS. Porto Alegre/RS. E-mail: joserobaina1326@gmail.com
} 
necessária integração interdisciplinar e transversal da Educação Ambiental no contexto escolar possibilitando uma aprendizagem significativa através da inclusão de importantes temáticas, na contextualização do ensino.

Palavras-chave: Rio Macaco, Bacia Hidrográfica, Educação Ambiental.

\section{Percepciones socioambientales de estudiantes de educación fundamental sobre Rio Macaco en Palmeira das Missões/RS}

Resumen: El Río Macaco en Palmeira das Missões/RS ha sufrido varios impactos causados por la acción antrópica. En este sentido, el presente artículo tiene como objetivo evaluar las percepciones socioambientales de los alumnos de 5 ㅇ a 9o grado de tres escuelas municipales de educación básica sobre el tema de la microcuenca del Río Macaco, mediante un cuestionario semiestructurado aplicado en diferentes regiones del municipio. Para el análisis de los resultados se utilizó la metodología cualitativa de Análisis de Contenido. Los resultados muestran que el conocimiento de los alumnos sobre el tema es inconsistente e inadecuado, lo que demuestra la importancia de una necesaria integración interdisciplinaria y transversal de la educación ambiental en el contexto escolar, que permita un aprendizaje significativo mediante la inclusión de temas importantes en la contextualización de la enseñanza.

Palabras-clave: Río Macaco, Cuenca Hidrográfica, Educación Ambiental.

\section{Socio-Environmental Perceptions of fundamental Education students about Rio Macaco in Palmeira das Missões/RS}

Abstract: The Macaco River in Palmeira das Missões/RS has been suffering several impacts caused by the anthropic action. Thus, this article aims to assess the socio-environmental perceptions of students from the 5 th to the 9th grade of three municipal elementary schools in the region of the Macaco river basin. The study is performed through a semi-structured questionnaire applied in different regions of the municipality. To process the results, the responses were analyzed through a qualitative methodology of Content Analysis was used. The results demonstrate that the students' knowledge of the theme is inconsistent and inadequate, demonstrating the importance of a necessary interdisciplinary and transversal integration of environmental education in the school context, which may enable meaningful learning through the inclusion of important themes in the context of teaching.

Keywords: Macaco River, Hydrographic Basins, Enviromental Education.

\section{Introdução}

A Educação Ambiental (EA) desempenha um papel essencial na formação de cidadãos preocupados com uma sociedade sustentável. Nas escolas, a EA tem o desafio de potencializar a consciência dos alunos sobre os problemas relacionados à crise socioambiental enfrentada na atualidade, promovendo boas relações entre eles e a natureza. Para que o processo de aprendizagem seja significativo, é preciso formar conexões entre os múltiplos aspectos cognitivos que ocorrem a nível individual com aqueles que ocorrem na sociedade (OLIVEIRA et al., 2017). Se entende que a aprendizagem se torna significativa conforme os conteúdos novos são inseridos a partir daqueles já presentes ou 
prévios oriundos da realidade do estudante. E um tema que pode ser trabalhado diz respeito aos rios, recursos hídricos, bacias hidrográficas e outros.

Portanto, diversos municípios brasileiros passaram a receber menores volumes de chuva desde 2012, gerando uma crise hídrica que afeta diretamente a oferta de água disponível para produção de alimentos, abastecimento público e geração de energia elétrica (ANA, 2017). A crescente crise hídrica enfrentada por diversas cidades evidencia a importância de trabalhar temáticas ambientais relacionadas a água nas escolas.

Para as ações praticadas nas escolas em relação às questões ambientais é importante discernir as concepções existentes entre ensinar e educar. No cotidiano da grande maioria das escolas são comuns atividades que ensinam os alunos a reconhecer as cores dos recipientes para a separação do lixo, elaborar cartazes para o consumo consciente da água, estudar manuais para classificar resíduos, entre tantas outras atividades pedagógicas necessárias. Contudo, a maioria destes alunos, ao saírem de suas escolas e se tornarem cidadãos que convivem com os mais diversos desafios em suas cidades ou em seus meios rurais, frequentemente agem de forma oposta aos seus aprendizados, mas ao contrário deveriam agir de forma ativa, se tornando assim um sujeito deste processo (KLAUSEN, 2017).

A existência destas discussões nas escolas está comprovada na medida em que sabemos que são claros os objetos do conhecimento exigidos nos documentos oficiais voltados para as instituições de ensino, tanto públicas como privadas, nas mais diversas áreas, relacionados aos cuidados do ambiente. Contudo, a contradição e o estranhamento se dão quando se percebem ações nocivas ao ambiente realizadas por pessoas que passaram por bancos escolares, portanto que vivenciaram estes objetos de conhecimento. $O$ questionamento que se faz é o que estas pessoas fizeram com suas aprendizagens remontadas em seus itinerários escolares sobre uma cidadania ambiental, pautada no reconhecimento e na mudança de cotidianos destrutivos do meio em que habitam e também habitarão seus descendentes.

Desta forma, a discussão que se faz para tentar responder sobre a fragilidade verificada na construção da cidadania e no contexto escolar está pautada, justamente na 
relação existente entre ensino e educação. Ensinar sobre as cores que estampam os recipientes de separação de resíduos não é a mesma coisa que educar os alunos para uma consciência ambiental. Ao termo "ensino", acopla-se mais facilmente a palavra "instrumental". Ao termo "educação", por sua vez, acopla-se mais facilmente a expressão “formadora para a vida" (REGO e COSTELLA, 2019). Desta forma, não há consciência crítica e reflexiva sem a instrumentalização, porém, somente a instrumentalização não garantirá a consciência crítica e reflexiva.

A EA perpassa pela observação atenta do lugar de vivência, interpretação destes lugares e fenômenos de forma reflexiva e crítica para a elaboração do pensamento e raciocínio ambiental que o cerca. Prestar a atenção e pensar no elemento natural como um processo e não como um objeto fixo, levará o aluno a educar o seu olhar para enxergar além do próprio elemento. Mesmo que o Rio Macaco fique mais distante para uns do que para outros, naquela escala municipal ele faz parte do lugar de vivência. Desta forma, os conceitos que instrumentalizam os alunos academicamente, como os ligados a hidrografia, devem estar vinculados aos elementos naturais que os cercam, as aprendizagens e as reflexões.

Neste caso, educar ambientalmente é provocar discussões e compreensões sobre a importância da água, partindo do contexto presente espacial e temporalmente, porém com o olhar apurado para o contexto espacial e temporal futuro (OLIVEIRA e TELES, 2015). Os manuais para o cuidado com a água se perderão nas lembranças dos alunos se somente ficarem no plano instrumental. O cuidado com a água ficará na concepção cidadã dos alunos se os mesmos se apropriarem dos seus contextos com autonomia e raciocínio ambiental para lutar com consciência crítica por uma vida melhor, tanto dele e dela como dos elementos naturais. Ao mencionar a experiência local como um ato educativo, não se quer reduzir o futuro cidadão somente para a sua cidade, a intenção é que a consciência reflexiva local permita a compreensão de como se lê ou se atua em escalas variadas no planeta.

O estudo, gerenciamento e intervenções ambientais em prol dos recursos hídricos devem ocorrer a nível de bacias hidrográficas. Todas as águas de uma bacia hidrográfica são escoadas para seus rios e afluentes, sendo influenciadas pelos processos climáticos, 
geológicos, hidrológicos e antropogênicos que nela ocorrem (OLIVEIRA et al., 2017; MARCHESAN et al., 2019). Além disso, as temáticas que envolvem o ambiente e a água podem ser trabalhadas de forma interdisciplinar nas instituições educacionais, favorecendo um aprendizado sistêmico que gera mudanças de comportamento e uma conscientização socioambiental (OLIVEIRA et al., 2017). Ademais, a contextualização das temáticas ambientais com os objetos do conhecimento construídos em sala de aula e com a realidade vivenciada fora da escola desperta o interesse dos alunos, favorecendo o processo de aprendizagem (PESSANO et al., 2015). Portanto, é crucial que todos os indivíduos de uma sociedade saibam sobre a bacia hidrográfica na qual estão inseridos e compreendam como suas ações afetam direta e indiretamente a quantidade e a qualidade das águas de sua região (MARCHESAN et al., 2019).

A microbacia hidrográfica do Rio Macaco, localizada na região sul do Brasil, está inserida na bacia hidrográfica do rio da Várzea e faz parte da região hidrográfica do Rio Uruguai. O Rio Macaco é a principal fonte de abastecimento de água e dessedentação animal do município de Palmeira das Missões, RS. A área da microbacia é de aproximadamente 3.700 hectares, com atividades relacionadas ao setor agropecuário ocupando cerca de dois terços dessa área. Soares (2018), em trabalho anterior nessa mesma área, identificou 127 nascentes que alimentam o Rio Macaco e ainda, que as matas ciliares ao redor destas se encontram degradadas. Além disso, o Rio sofre diversos outros impactos ambientais como assoreamento e a contaminação do solo e da água por agrotóxicos e fertilizantes agrícolas. Todos esses impactos afetam a qualidade e quantidade de água do Rio Macaco. Devido à importância do Rio para o município foi instituído o Plano Diretor Participativo que estabeleceu a Microbacia do Rio Macaco como zona de preservação:

I - Zona Especial da Microbacia do Arroio Macaco, na sua localização acima do ponto de captação de água da CORSAN, para fins de preservação ambiental e melhoria quantitativa e qualitativa do referido manancial hídrico, cuja água é utilizada para o abastecimento da comunidade palmeirense (PALMEIRA DAS MISSÕES, 2013, p. 15).

Além disso, o Plano Diretor apresenta diretrizes de política ambiental municipal que visam a promoção da EA, de forma contínua e integrada, para o desenvolvimento de políticas públicas sustentáveis, proteção e recuperação do meio ambiente, redução da 
poluição e degradação ambiental, informação da população a respeito dos serviços de saneamento e preservação dos recursos hídricos (PALMEIRA DAS MISSÕES, 2013). A escola e os espaços educativos são excelentes locais para a inserção da EA, com potencial de estimular o interesse dos alunos nas questões ambientais vivenciados por eles. A EA contínua favorece a adoção de comportamentos e atitudes necessárias para atuar de forma crítica e comprometida com os problemas do contexto ambiental de sua realidade, integrando o indivíduo ao meio em que vivem (PESSANO et al., 2014). Diante do exposto, este estudo tem o objetivo de verificar as percepções socioambientais de estudantes do Ensino Fundamental referente ao Rio Macaco, em escolas da rede municipal de Palmeira das Missões/RS, como ferramenta promotora para ações de EA nas referidas escolas.

\section{Pressupostos Metodológicos}

O trabalho foi realizado no de 2020 em três escolas públicas localizadas em diferentes regiões do município de Palmeira das Missões/RS. A seleção das escolas foi pensada de forma estratégica por possuírem características e perfis diferentes em termos de estudantes, professores e localização geográfica em relação ao Rio Macaco. Elas foram classificadas conforme a ordem de aplicação do questionário.

A escola " $A$ " fica a oito km de distância do Rio e está situada na periferia da cidade. A escola "B" fica a $30 \mathrm{~km}$ do Rio e está situada na zona urbana, sendo incluída no estudo por ser a maior escola do município, e a escola " $C$ ", por sua vez, fica a cinco km de distância do Rio e está situada na zona rural do município. O nome das escolas foi omitido para não expor estas instituições e as comparações realizadas entre elas.

Para verificar as percepções dos estudantes sobre a temática proposta, um questionário semiestruturado foi aplicado a 44 estudantes cursando do 50 ao 90 ano das respectivas escolas participantes dessa pesquisa. O questionário coletou informações da realidade dos participantes sobre questões referentes a quatro aspectos distintos do Rio Macaco: 1) questões pertinentes ao conhecimento geral dos alunos sobre o Rio; 2) questões sobre o relacionamento dos alunos e da escola com o Rio; 3) questões sobre a importância 
do Rio para o município e os problemas ambientais existentes na área e; 4) questões sobre a bacia hidrográfica na qual o Rio Macaco está inserido.

Esta pesquisa foi registrada junto à Pró-Reitoria de Pesquisa da Universidade Federal do Rio Grande do Sul e aprovado pelo Comitê de Ética e Pesquisa - CEP sob o número 22437219.6.0000.5347.

Os dados produzidos foram analisados a partir da aplicação de um conjunto de técnicas conforme a Análise de Conteúdo (BARDIN, 2011). Ela pode ser definida como:

\footnotetext{
Um conjunto de instrumentos metodológicos cada vez mais sutis em constante aperfeiçoamento, que se aplicam a 'discursos' [...] diversificados. O fator comum dessas técnicas múltiplas e multiplicadas [...] é uma hermenêutica controlada, baseada na dedução: a inferência. Enquanto esforço de interpretação, a análise de conteúdo oscila entre os dois polos do rigor da objetividade e da fecundidade da subjetividade (BARDIN, 2011, p. 15).
}

Mais especificamente, dentro dessa metodologia de análise, encontramos diversas técnicas que proporcionam melhores formas de interpretação aos autores. Para este trabalho, considerando os objetivos, a problemática, o público-alvo e o contexto de pesquisa, optamos pela Análise proporcional do discurso, que permitiu estabelecer ligações entre a situação em que o sujeito da pesquisa se encontra e as manifestações semânticosintáticas dos seus discursos, e a Análise das relações, a qual permitiu interpretações e compreensões das relações que os elementos textuais mantêm entre si, possibilitando um olhar para além da visão sistêmica (BARDIN, 2011).

\section{Resultados e discussão}

Os alunos participantes da pesquisa tinham entre 10 e 18 anos, apresentando uma idade média de 13 anos. Aproximadamente dois terços dos alunos eram meninos, representando $65,9 \%$ dos participantes e $34,1 \%$ meninas. Destes $20 \%$ cursavam o 50 ano, $39 \%$ dos alunos cursavam o sexto, $11 \%$ o sétimo ano, $20 \%$ o oitavo ano e apenas $10 \%$ o nono ano do Ensino Fundamental. A distribuição das proporções de estudantes por escola foi bastante assimétrica. A escola B teve o maior número de participantes (26), devido ao fato dessa ser a escola maior do município. Já as escolas A e C tiveram nove participantes cada. 
Quando analisado todas as escolas, verifica-se que mais da metade dos alunos participantes afirmam não conhecer o Rio Macaco, nem o visitaram pessoalmente (Figura 1). Esse resultado diverge daquele encontrado por Soares et al. (2018), onde a maioria dos alunos do ensino médio de Palmeiras das Missões afirmaram ter conhecimento sobre o Rio Macaco e outros da região. Essa divergência demonstra que o uso da temática Rio Macaco pode não estar ocorrendo de forma sistêmica em todas as escolas do município e ao longo de todo a educação básica dos alunos.

Um resultado interessante ocorreu na escola $C$, na qual todos os alunos afirmaram conhecer o Rio Macaco, diferentemente dos alunos da escola A, 56\% afirmou conhecer e da Escola B, onde apenas $27 \%$ afirmou conhecer o Rio.

Ressalta-se que muitos alunos da escola C são filhos de agricultores e trabalhadores rurais, os quais podem ter o Rio de forma mais próxima em suas vivências e realidades. Houve ainda, uma diferença nos resultados, sobre o conhecimento do Rio e o ano escolar cursado, onde os estudantes do $7^{\circ}$ ano apresentaram uma maior proporção de resposta $(76,9 \%)$ afirmando que conheciam o Rio, em relação aos outros anos escolares. Entre os alunos que já visitaram o Rio, a maioria afirmou ter ido com os pais $(58,8 \%)$ ou com a escola $(23,5 \%)$ (Figura 1$)$.

A escola C apresentou a maior proporção de alunos levados ao Rio (80\%), enquanto nenhum dos alunos das outras escolas visitou o Rio por meio de iniciativa da instituição (Figura 2). A proximidade da escola $C$ ao Rio Macaco pode também ter favorecido o desenvolvimento de atividades junto ao respectivo ambiente. De acordo com Pessano et al. (2014) isso também foi observado em seus estudos, onde pode ocorrer uma associação positiva entre a distância das escolas em relação ao Rio Uruguai e concluíram que as escolas mais próximas do Rio desenvolvem mais atividades junto a ele do que escolas mais distantes. Entretanto, o fato de todos os alunos que visitaram o Rio junto com a escola serem do $7^{\circ}$ ano demonstra que mesmo na escola $C$, as visitas ao Rio não ocorrem de forma planejada e contínua ao longo do Ensino Fundamental.

Em relação a esta análise reforça-se a ideia levantada anteriormente sobre o que se faz com os instrumentos que se tem no ato de ensinar e educar. O contato com o Rio não se 
dá de forma contínua, complexa e reflexiva. O contato se dá na dependência da intenção do professor ou da turma. Para que os alunos se eduquem ambientalmente os projetos precisam ser emanados de uma gênese escolar e não identitária de um ou outro professor. Olhar o Rio como parte de si mesmo e compreender o significado de sua existência atrelada à existência da população não se configura de ações esporádicas, mas sim de ações contínuas horizontalizadas pelos eventos interdisciplinares e verticalizadas pelas relações de aumento de complexidade na interpretação dos elementos configurantes do contexto, em diferentes níveis de aprendizagem.

Além disso, apesar do Rio ser de jurisdição municipal, nenhum aluno declarou ter visitado o Rio por meio de ações proporcionadas pela prefeitura. Esse fato evidencia a inobservância da prefeitura em relação ao Plano Diretor do próprio município. Em muitos casos, os próprios gestores públicos não possuem um conhecimento aprofundado sobre os recursos hídricos existentes na região (SOARES, 2018).

Ações públicas são fundamentais para a EA. Entretanto, é preciso superar visões de gestão ultrapassadas para fortalecer as articulações entre políticas públicas e a sociedade, para assim gerar ações efetivas e duradouras de recuperação e preservação dos recursos hídricos (JACOBI; FRACALANZA; SILVA-SÁNCHEZ, 2015).

Menos de $25 \%$ dos alunos afirmaram que suas escolas já realizaram alguma atividade junto ao Rio Macaco (Gráfico 2). Essa situação foi ainda mais crítica na escola $A$, onde nenhum dos alunos declarou ter participado de atividades relacionadas ao Rio no ambiente escolar. Esses dados evidenciam que o Rio Macaco não é frequentemente utilizado como temática ambiental nas práticas pedagógicas das escolas avaliadas, mesmo que ele seja fundamental para o município.

A principal atividade citada por alunos das escolas $B$ e $C$ foi relacionada à estação de captação de água, mas na escola $C$ os alunos também citaram atividades como passeio e os estudos do meio e da biodiversidade. Nenhum dos alunos participou de atividades envolvendo a avaliação dos problemas ambientais nem sobre a qualidade e quantidade da água do Rio. Isso demonstra que as temáticas relacionadas aos impactos socioambientais não foram desenvolvidas eficientemente em nenhuma das escolas. 


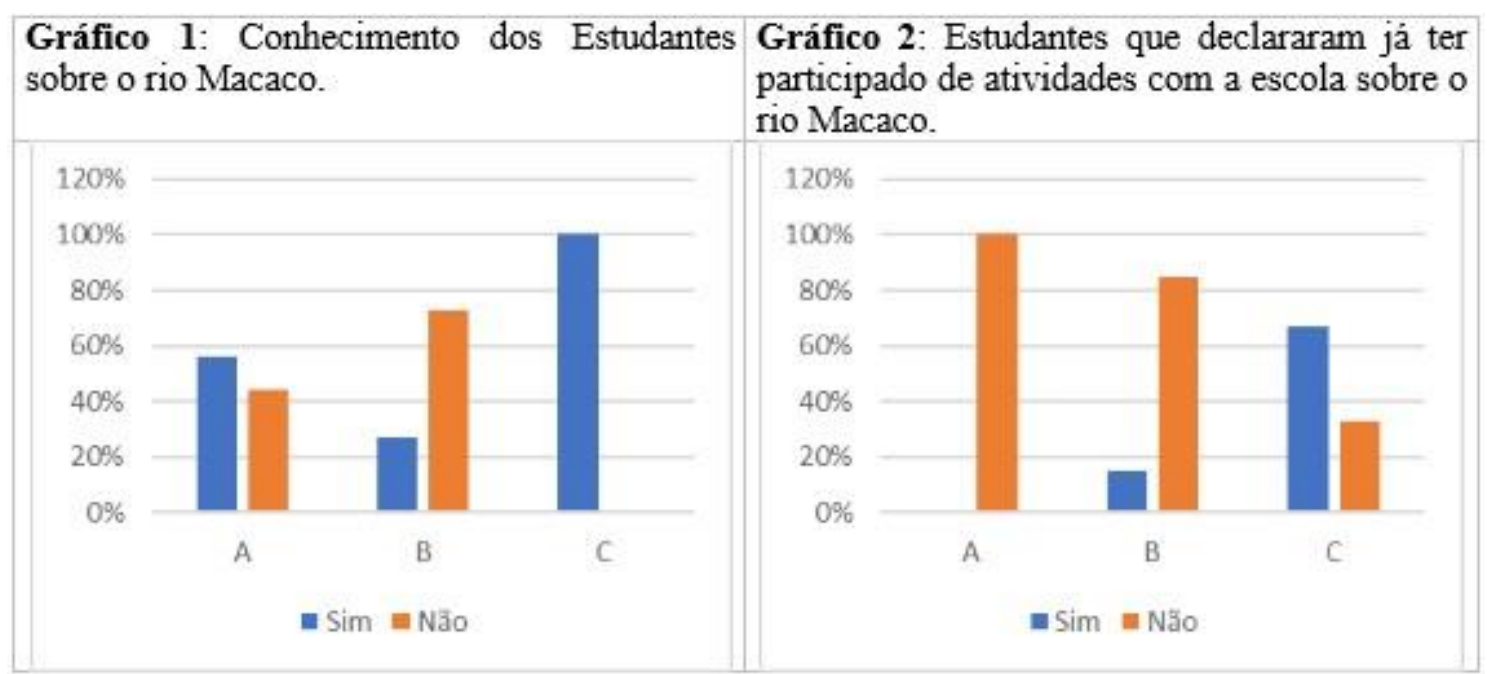

Fonte: Autores, 2020.

Houve uma diferença na resposta sobre a abordagem dessas temáticas em sala de aula em relação ao sexo, com os meninos apresentando uma proporção superior de respostas positivas em comparação as meninas. Entretanto, quase três quartos dos alunos declararam que as demais temáticas ambientais não são abordadas em sala de aula, principalmente os alunos da 8a e 9a série (Gráfico 3). Quando as temáticas eram abordadas, elas se limitavam principalmente as disciplinas de Geografia e, em menor frequência, História e Ciências (Gráfico 4). Nenhum outro conteúdo/disciplina foi citado pelos alunos. Isso demonstra a falta de abordagem interdisciplinar e transversal sobre a temática, o que resulta em um conhecimento fragmentado.

A integração da EA na sala de aula pode ser feita de acordo com o plano de ensino e com a realidade dos alunos tendo como base o currículo de cada Instituição de Ensino (SACRISTÁN, 2000), utilizando os mesmos materiais de ensino já aplicados nas escolas. Os professores precisam conectar temáticas ambientais a pontos relevantes de suas disciplinas, expondo regularmente os alunos aos problemas ambientais a fim de potencializar as reflexões e ações críticas e transformadoras. No entanto, para que isto aconteça, sabemos que há necessidade de formações iniciais e continuadas para que os docentes se sintam preparados para o trabalho com a EA. 
Gráfico 3: Em sala de aula são abordadas as Gráfico 4: Em qual disciplina é abordada as temáticas relacionadas as atividades anteriores. atividades.

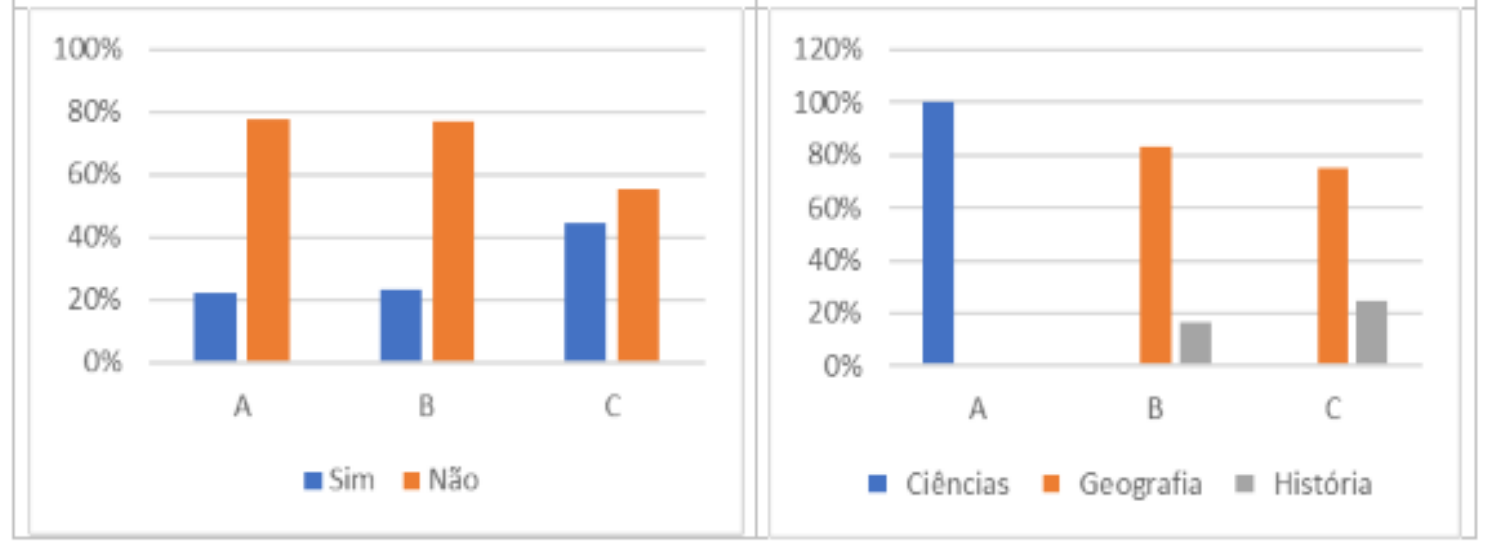

Fonte: Autores, 2020.

A temática poderia, por exemplo, ser explorada em aulas de português (como tema de redação ou por interpretação de textos ligados à temática), artes (utilizando o Rio como forma de inspiração), matemática (por meio de cálculos de dimensões do Rio, volumes de água, profundidade e uso racional dos recursos hídricos) e educação física (desenvolvendo atividades ao ar livre, como caminhadas ao longo do Rio) entre outras disciplinas. A implementação de práticas interdisciplinares de EA acelera a construção de um senso comunitário, facilitando a transformação de modelos de sociedade não sustentáveis para sustentáveis, sem comprometer a cultura e a produtividade regional (SANTOS JÚNIOR et al., 2013).

Para que se desenvolva um trabalho interdisciplinar nas escolas não basta que se tenha um tema em comum, precisa-se uma reflexão pedagógica muito maior do que a integração temática entre componentes curriculares. A interdisciplinaridade se constrói primeiramente na formação do professor. Ser interdisciplinar é conceber que a disciplina de cada um pode e deve desenvolver competências necessárias para a formação de um aluno de forma integral (SOUZA e OLIVEIRA, 2011). Neste caso, o tema água não pressupõe que cada professor retire de sua ciência tudo o que aborda a água em si. O que está se discutindo é uma competência para o desenvolvimento da consciência ambiental. Para este desenvolvimento não basta a Geografia localizar os Rios e a Ciência falar sobre a vida que nele existe. Para construir um aluno consciente o professor de Geografia deve, além de 
instrumentalizar conceitualmente sobre a localização, intencionar um olhar contínuo dos fenômenos que este Rio provoca neste lugar. O professor de Ciências deve promover o significado da vida nestas águas e não meramente a descrição desta vida relacionada à existência deste elemento natural (BACCl e PATACCA, 2008).

Os alunos também foram questionados sobre a importância do Rio para o município, os principais problemas socioambientais enfrentados por ele e a percepção do aluno enquanto sujeito social capaz de modificar a realidade do mesmo (Gráficos 5 e 6). Quase 90\% dos alunos declararam que o Rio Macaco tem um papel importante para o município de Palmeira das Missões. A principal relevância atribuída ao Rio foi o abastecimento de água da região $(51,3 \%)$.

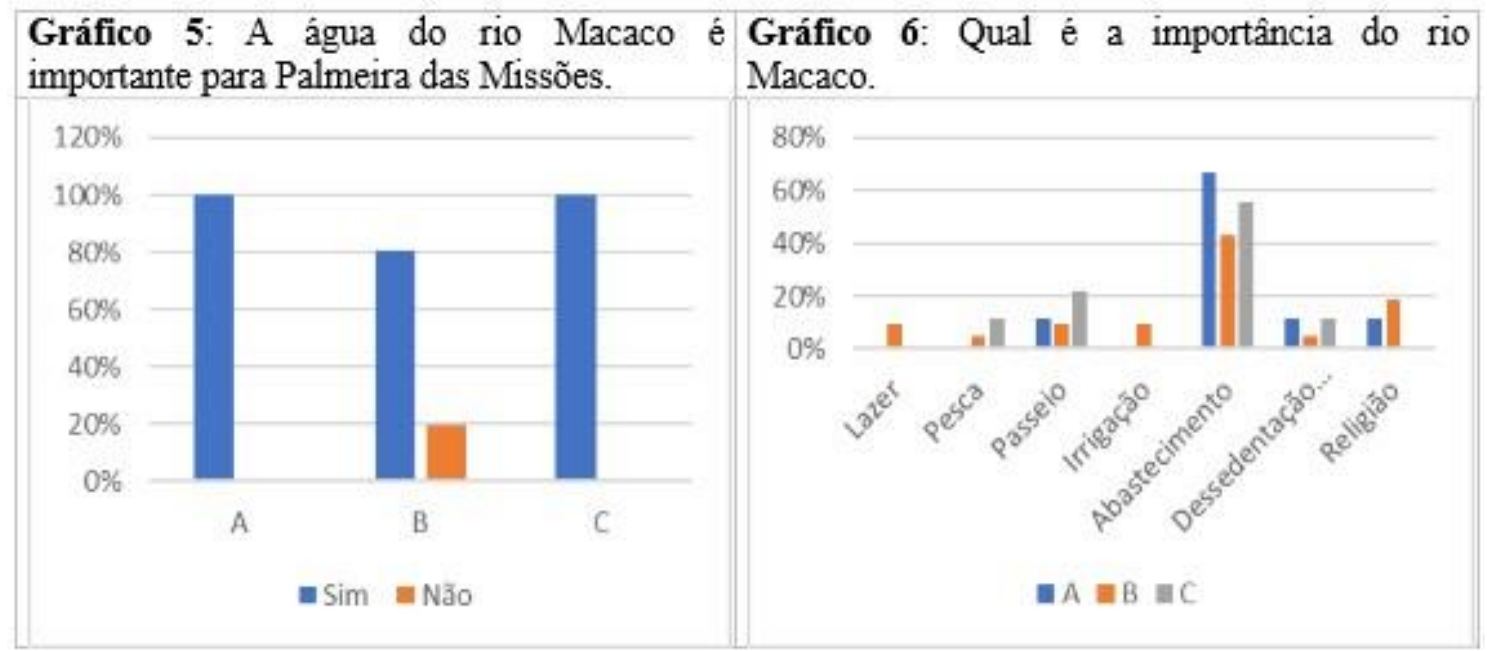

Fonte: Autores, 2020.

A análise num plano simplista da utilização do Rio denota a relação direta entre a existência dos elementos naturais como função de satisfazer a existência humana. O Rio Macaco serve para o abastecimento de água e para tantas outras coisas. Esta lógica simplista e pouco reflexiva é comum quando se instrumentaliza sem educar. O potencial educativo está em discernir com certa complexidade as relações entre o Rio Macaco e o espaço adjacente, entre diferentes formas de vida, que não se resumem aos humanos e, principalmente, a uma continuidade de elementos que não devem ser analisados de forma fragmentada na concepção educativa de mundo. O Rio Macaco faz parte de um quadro 
paisagístico articulado a outros e mais outros, necessários para uma compreensão competente do ambiente em diferentes escalas e em diferentes situações vividas no presente e no futuro.

Em relação aos problemas socioambientais existentes no Rio Macaco, apenas 20,5\% dos alunos afirmaram conhecê-los. Houve uma diferença significativa entre as escolas, com mais da metade dos alunos da escola $\mathrm{C}$ afirmando conhecer os problemas socioambientais do Rio em comparação com apenas $11 \%$ dos alunos das outras escolas (Gráfico 7).

Os principais problemas citados entre os alunos que afirmaram conhecê-los foram o desmatamento das margens, poluição por defensivos agrícolas e esgoto, assoreamento do leito do rio, erosão de suas margens e instalação de barramentos. Esses problemas condizem com a realidade do lugar e o desmatamento das matas ciliares é o principal problema ambiental enfrentado pelo rio (SOARES, 2018). Esses problemas são característicos de diversos cursos d'água (LIMA, 2010; PESSANO et al., 2014), sendo frequentemente abordados nos meios de comunicação. A grande proporção de alunos alheios a eles indica que esses problemas ambientais não são propriamente trabalhados no ambiente escolar.

Apenas cerca de $33 \%$ dos alunos indicaram saber quem eram os responsáveis por causar os problemas socioambientais existentes no Rio Macaco (Gráfico 8). Os principais atores citados como responsáveis por estes ao longo do Rio foram a população em geral, a atual matriz produtiva, os proprietários de indústrias, e os poderes públicos municipal, estadual e federal. Silva (2017) também observou uma responsabilização da população em geral, entretanto, os alunos responsabilizaram principalmente a população residente no entorno do Rio analisado. 


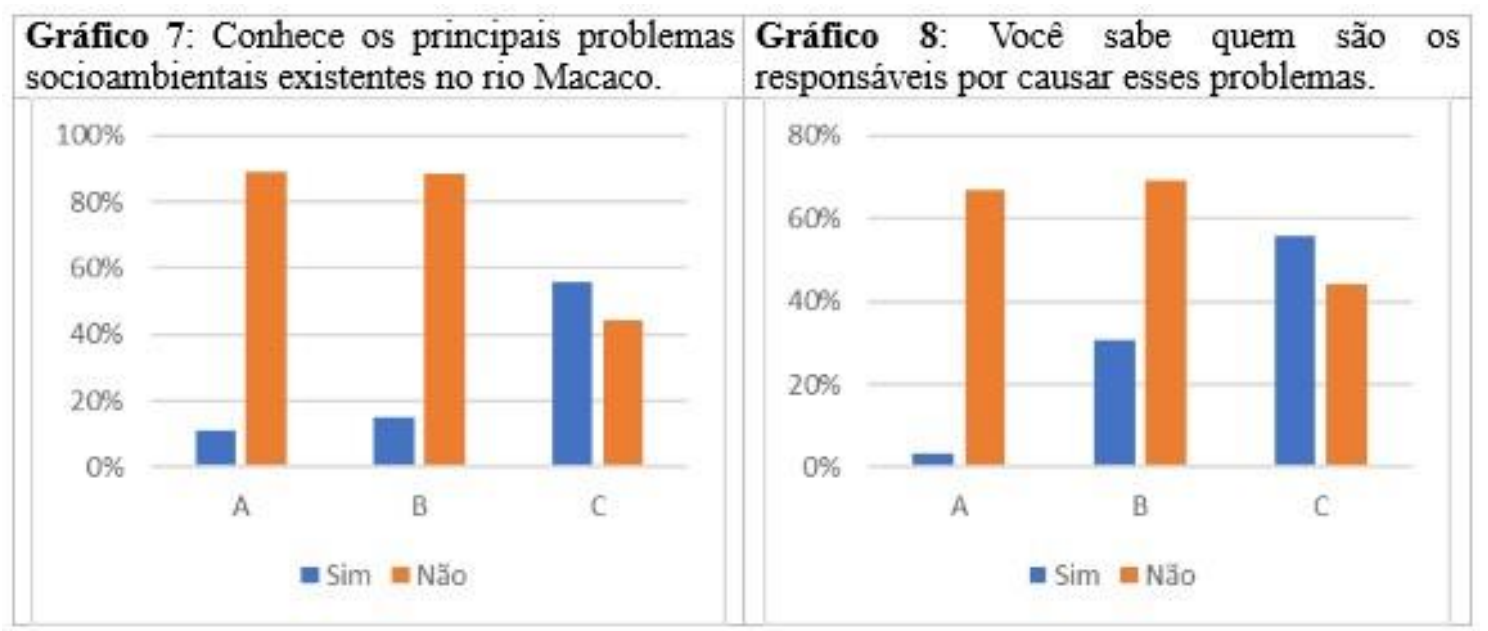

Fonte: Autores, 2020.

Mesmo desconhecendo os problemas socioambientais relacionados ao Rio Macaco, 79,5\% dos alunos afirmam poder contribuir para melhorar as condições a que este lugar se encontra, citando como opção de ação, principalmente, a economia de água. Não houve associações significantes entre essas questões e o sexo, escola ou ano cursado pelos alunos. Entretanto, ressalta-se que uma proporção menor de meninos soube responder quem são os responsáveis pelos problemas socioambientais do Rio em comparação com as meninas.

A ação diante de uma situação em que se exige a reflexão sempre se dá de forma articulada e fundamentada. Quando não se reflete sobre as ações, as respostas emergem das informações, tanto provindas de veículos midiáticos, como provinda de conceitos escolares pouco ressignificados a partir do local de vivência. Novamente ressurge a ideia de que a informação não significa conhecimento, a instrumentalização não significa a educação. As respostas simplistas e repetitivas dos alunos requerem dos educadores uma reavaliação das metodologias utilizadas na concepção da consciência educativa.

Os alunos também responderam questões que pretendem saber de onde vem a água que abastece a cidade de Palmeira das Missões se sim ou não e qual a origem (Gráfico 9 e 10). Apesar de aproximadamente $33 \%$ dos alunos afirmarem saber a origem da água que abastece a região, apenas $48,4 \%$ deles respondeu que ela se origina no Rio Macaco. Houve uma diferença significativa entre a resposta dos alunos de acordo com o sexo, com $86,2 \%$ 
dos meninos afirmando conhecer a origem da água enquanto menos da metade das meninas afirmaram o mesmo.

A água que abastece a região é literalmente a água que os abastece. Nesta questão fica aparentemente demonstrada a condição de que tudo o que se aprende é sobre o outro e não sobre nós mesmos. Bebe-se constantemente a água, utiliza-se constantemente este elemento natural, porém sabe-se parcialmente da sua origem e, geralmente quando se sabe, parece estar distante das relações existentes para que este elemento seja preservado e porque deve ser preservado.

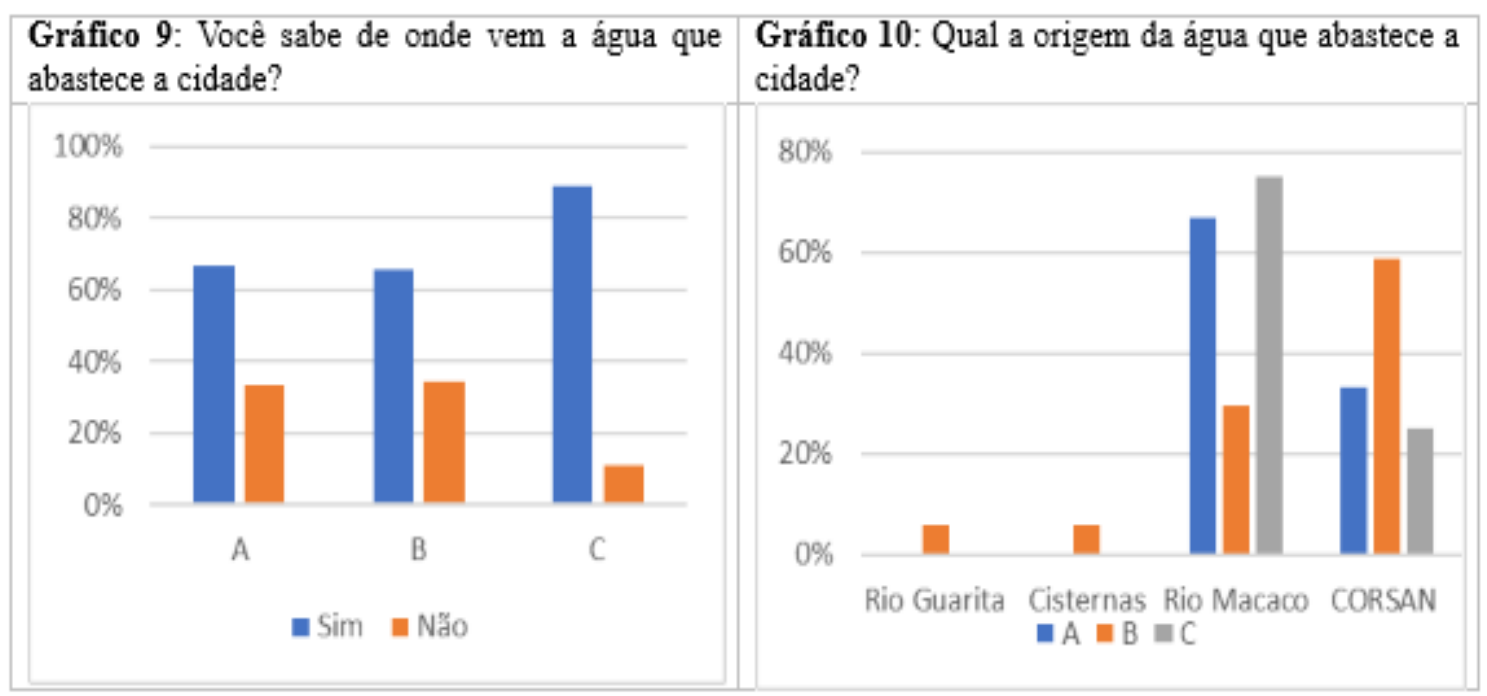

Fonte: Autores, (2020).

A Corsan foi a segunda opção mais selecionada pelos alunos (45,2\%). A Corsan é a Companhia Riograndense de Saneamento, empresa responsável pelo abastecimento da região. O equívoco entre o Rio que fornece a água e a empresa captadora e distribuidora da mesma evidencia falhas no conhecimento dos alunos sobre a origem da água que abastece a sua cidade.

Ainda, visando complementar as questões foi perguntado aos estudantes o que entendiam como bacia hidrográfica, a maioria dos alunos não souberam definir o que é uma bacia hidrográfica (73\%). Entre os que afirmam saber o que é uma bacia hidrográfica, 88,9\% deles indicaram ter aprendido sobre a temática na escola (88,9\%). Cabe ressaltar que 
nenhum aluno da escola $C$ soube responder o que é a bacia hidrográfica enquanto os alunos da escola B teve a menor proporção de respostas negativas. As principais definições fornecidas foram área de grande concentração de água ou definições relacionadas ao abastecimento público, economia, água. Entretanto, a bacia hidrográfica engloba toda uma região onde ocorrem "os balanços de entrada proveniente da chuva e saída de água por meio do exutório [...]. Todas as áreas urbanas, industriais, agrícolas ou de preservação fazem parte de alguma bacia hidrográfica" (PORTO; PORTO, 2008, p.45).

As respostas dos alunos demonstram que o conceito de bacia hidrográfica não é claro nem para os alunos que afirmam ter conhecimento sobre a temática. Apesar de associarem o conceito aos recursos hídricos, eles não compreendem que outros elementos biofísicos, como o solo de drenagem e o ambiente circundante, também fazem parte da bacia hidrográfica. Silva (2017) também observou uma compreensão simplista sobre esse conceito entre alunos do ensino médio.

Dentro de uma bacia hidrográfica pode haver diversas sub-bacias ou microbacias, que são interconectadas pelos sistemas hídricos (PORTO; PORTO, 2008). Neste contexto o rio Macaco por sua extensão e largura se enquadra como uma microbacia, a qual pode ser conceituada como uma:

\footnotetext{
Unidade básica de planejamento para compatibilização da preservação dos recursos naturais e da produção agropecuária. As microbacias hidrográficas possuem características ecológicas, geomorfológicas e sociais integradoras, o que possibilita a abordagem holística e participativa, envolvendo estudos interdisciplinares para o estabelecimento de formas de desenvolvimento sustentável inerentes ao local e região onde forem implementados (ATTANASIO, 2004, p.02).
}

Segundo Hespanhol (2005, p. 05), “as microbacias hidrográficas normalmente abrangem superfícies territoriais que variam de 3 a 10 mil hectares. São superfícies compreendidas entre o fundo de vale e os espigões divisores de água", esses dados vão ao encontro dos achados nesta pesquisa. Palmeira das Missões se situa na microbacia do Rio Macaco que faz parte da bacia hidrográfica do Rio Uruguai. Neste estudo, apenas $22,7 \%$ dos alunos disse saber em qual bacia hidrográfica a cidade se encontra. Entretanto, menos de $15 \%$ do total de alunos participantes responderam que a cidade de Palmeira das Missões se encontra no entorno do Rio Macaco e este faz parte da grande bacia do Rio Uruguai. A falta 
de conhecimento sobre o Rio Macaco, incluindo a sua importância socioeconômica e ambiental para a região onde vivem, e sobre o conceito de bacia hidrográfica evidencia a falta de foco direcionado a essas temáticas nas escolas analisadas.

Apesar da importância da EA para a formação de cidadãos e para a utilização sustentável dos recursos naturais, nota-se que existe uma falha generalizada na inserção dessa temática no ambiente escolar (PESSANO et al., 2014; LEITE et al., 2015; OLIVEIRA; MACHADO; OLIVEIRA, 2015; PESSANO et al., 2015; QUEIROZ et al., 2015).

Os aspectos mencionados anteriormente resultam em uma baixa percepção socioambiental dos alunos quanto a importância de recuperar área degradadas e preservar recursos naturais vitais para a existência humana, como a água. A implementação de atividades de intervenção costuma melhorar rápida e significativamente as concepções dos alunos sobre questões ambientais (OLIVEIRA; MACHADO; OLIVEIRA, 2015; PESSANO et al., 2015; QUEIROZ et al., 2015).

Portanto, para uma eficaz integração da EA nos currículos dessas escolas seria preciso envolver alunos e docentes em atividades pedagógicas inovadoras, que visem a preservação de recursos naturais e contribuam para o estabelecimento de ações sustentáveis. A EA precisa ser promovida de forma interdisciplinar e contextualizada com os conteúdos já lecionados em sala de aula. A incorporação dos rios como temática ambiental dinamiza as práticas pedagógicas e torna o processo de aprendizagem mais instintivo e interessante para os alunos (PESSANO, 2012).

\section{Considerações Finais}

Este estudo avaliou a percepção dos alunos do ensino fundamental de três escolas públicas sobre a temática Rio Macaco, o qual é a principal fonte de abastecimento de água do município de Palmeira das Missões e de prover diversos outros serviços ecossistêmicos para a região. Os resultados demonstram que o conhecimento dos alunos sobre a temática não é adequado, indicando que o Rio Macaco é pouco utilizado como temática nas escolas avaliadas e pouca ênfase é dada a sua importância. 
A deficiência na integração desta temática ambiental nas ações pedagógicas foi mais evidente nas escolas mais distantes do Rio. As percepções inconsistentes e inadequadas dos alunos em relação ao Rio salientam a importância de uma integração interdisciplinar e transversal da temática no contexto escolar. Assim, além das escolas se adequarem às especificações da legislação atual, elas poderão fornecer uma aprendizagem mais holística e contextualizada com a realidades dos alunos e professores.

Futuras pesquisas devem focar na implementação de ações educacionais que facilitem a incorporação das temáticas ambientais rio e bacia hidrográfica em diferentes disciplinas ao longo do Ensino Fundamental, envolvendo tanto os educandos quantos os educadores nessas ações.

Este trabalho, assim como os próximos que emergirem do mesmo, tem grande contribuição à ciência, uma vez que não é possível desarticular a formação para a cidadania socioambiental de uma formação para o meio científico. No momento em que os processos educativos tiverem como centro a formação para a ciência, os sujeitos estarão potencializando sua consciência crítico-reflexiva para debater problemáticas sociais, minimizar ou solucionar problemas dos lugares a que se sentem pertencentes, bem como estabelecer conexões do local com o global, compreendendo que as somas das partes transcendem a totalidade da vida.

Estas considerações - "nem tão" finais promovem uma discussão que, apesar de recorrente ainda precisamos estabelecer na relação entre o ensino e a aprendizagem e o ensino e a educação. A pesquisa demonstra que se faz necessário para o desenvolvimento da EA uma postura mais reflexiva sobre o local, não se limitando a rios ou a vegetações, mas ampliando o olhar de forma mais reflexiva sobre as relações existentes nos locais de vivência. Estudar de forma interdisciplinar o lugar significa aprender a aprender sobre ele. Se o aluno aprender a aprender, seguramente saberá ler outros lugares que um dia poderá ser a sede da sua própria cidadania. Cidadania e educação não se resumem a instrumentalizações e objetos, mesmo sabendo que sem estes não há reflexão. 


\section{Referências}

ANA. Agência Nacional de Águas. Conjuntura dos recursos hídricos no Brasil 2017: relatório pleno. Brasília: Ana.

ATTANASIO, Cláudia Mira. Plano de manejo integrado de microbacias hidrográficas com uso agrícola: uma abordagem na busca da sustentabilidade (Tese de Doutorado). Escola Superior de Agricultura "Luiz de Queiroz" - ESALQ, USP, São Paulo, SP, Brasil, 2004.

BACCI, Denise de La Corte.; PATACA, Ermelinda Moutinho. Educação para a água. Estudos Avançados. vol.22 no.63 São Paulo, 2008. https://doi.org/10.1590/S010340142008000200014.

BARDIN, Laurence. Análise de Conteúdo. São Paulo: Edições 70, 2011.

CARVALHO, Luiz Marcelo de. A temática ambiental e o processo educativo: dimensões e abordagens. In: CINQUETTI, Heloísa Chalmers Sisla.; LOGAREZZI, Amadeu. (Orgs.). Consumo e Resíduo - Fundamentos para o trabalho educativo. São Carlos: EdUFSCar, 2006. p.19-41. (Vol. 1).

HESPANHOL, Antonio Nivaldo. O programa de microbacias hidrográficas e a questão do desenvolvimento de territórios rurais no Estado de São Paulo - Brasil. In: 4tas. Jornadas Internacionais de Estúdios Agrários y agroindustriales, Facultad de Ciências Econômicas, UBA, Buenos Aires, 2005. p 20, 2005.

JACOBI, Pedro Roberto., FRACALANZA, Ana Paula., SILVA-SÁNCHEZ, Solange. Governança da água e inovação na política de recuperação de recursos hídricos na cidade de São Paulo. Cadernos Metrópole,17 (33), 61-81, 2015.

KLAUSEN, Luciana dos Santos. Aprendizagem Significativa: Um Desafio, 2017. In: IV Seminário Internacional de Representações Sociais, Subjetividade e Educação - SIRSSE, VI Seminário Internacional sobre Profissionalização Docente (SIPD/Cátedra UNESCO). Disponível em: https://educere.bruc.com.br/arquivo/pdf2017/25702 12706.pdf. Acesso em: 23 set 2020.

LIMA, Aguinel Messias de. 0 rio Paraguai como tema gerador de ações em educação ambiental escolar no município de Cáceres - Mato Grosso. (Tese de Doutorado). Universidade Federal de São Carlos, São Carlos, Brasil, 2010.

LEITE, Danuza Costa., DOURADO, Thania Maria Fonseca Aires., MARTINS Albert Lennon Lima., DOURADO, Joseano Carvalho., OLIVEIRA, Juliana Silva de., CARRIJO, Alexandre 
Giuliano. Percepção ambiental em escolas rurais: subsídios para Educação Ambiental. Revista Brasileira de Educação Ambiental (RevBEA), 10 (3), 134-146, 2015.

MARCHESAN, Jairo., MILANI, Maria Luiza., GUMBOWSKY, Argos., BAZZANELLA, Sandro Luiz. Bacia hidrográfica como possibilidade de intervenção e educação ambiental: o caso do lajeado Sabão, no município de Concórdia (SC). In: Seminário internacional sobre desenvolvimento regional, 9., 2019, Santa Cruz do Sul. Anais (p. 1-19). Santa Cruz do Sul: Universidade de Santa Cruz do Sul.

OLIVEIRA, Jeane Teresinha de.; MACHADO, Rita de Cássia Dallago.; OLIVEIRA, Everton Mário de. Educação ambiental na escola: um caminho para aprimorar a percepção dos alunos quanto à importância dos recursos hídricos. Periódico Eletrônico Fórum Ambiental da Alta Paulista, 11(4), p. 311-324, 2015.

OLIVEIRA, Marcia Maria Dosciatti de., MENDES, Michel., HANSEL, Claudia Maria., DAMIANI, Suzana. (Orgs.). Cidadania, meio ambiente e sustentabilidade. Caxias do Sul: Educs, 2017. OLIVEIRA, João Paulo Camilo de.; TELES, Diego Alves. Educação Ambiental: Discurso ou Realidade no cotidiano escolar?, 2015. Disponível em:

http://www.revistaea.org/artigo.php?idartigo=1993. Acesso em 23 set 2020.

PESSANO, Edward Frederico Castro. 0 uso do rio Uruguai como tema gerador para a educação ambiental no ensino fundamental. (Dissertação de Mestrado). Universidade Federal de Santa Maria, Santa Maria, 2012.

PESSANO, Edward Frederico Castro., DÁVILA, Eliziane da Silva., SILVEIRA, Marlise Grecco de Souza., PESSANO, Claudia Lisiane Azevedo., FOLMER, Vanderlei., PUNTEL, Robson Luiz. Percepções socioambientais de estudantes concluintes do ensino fundamental sobre o rio Uruguai. Revista Ciências \& Ideias, 4 (2), 61-84, 2014.

PESSANO, Edward Frederico Castro., PESSANO, Claudia Lisiane Azevedo., FOLMER, Vanderlei., PUNTEL, Robson Luiz. O rio Uruguai como tema para a Educação Ambiental no Ensino Fundamental. Revista Contexto \& Educação, 30(96), 29-63, 2015.

PORTO, Mônica Ferreira do Amaral., PORTO, Rubem La Laina. Gestão de bacias hidrográficas. Estudos avançados, 22(63), 43-60, 2008.

PALMEIRA DAS MISSÕES. Lei Complementar № 52, 18 de dezembro De 2013. Plano Diretor Participativo do município de Palmeira das Missões - RS, dezembro de 2013. Disponível em: https://leismunicipais.com.br/plano-diretor-palmeira-das-missoes-rs. Acesso em: 24 ago 2020. 
QUEIROZ, Thayline Vieira., CARDOZO, Bruna Santos., ROCHA, Bianca Oliveira., DORNFELD, Carolina Buso. Ensino sobre Bacias Hidrográficas no Ensino Fundamental: Uma Perspectiva na Educação Ambiental. In: Encontro Pesquisa em Educação Ambiental. Anais (p. 1-15). Rio de Janeiro: Unirio, 2015.

REGO, Nelson. COSTELLA, Roselane Zordan. Educação geográfica e ensino de Geografia, distinções e relações em busca de estranhamentos. Revista Signos Geográficos - Boletim NEPEG de ensino de Geografia - ISSN: 2675-1526. 2019. P. 01 a 15.

SACRISTÁN, José Gimeno. O currículo: uma reflexão sobre a prática. Porto Alegre: Artmed, 2000.

SILVA, Carmem Lúcia Rosa da. Percepção ambiental de alunos do colégio de aplicação da UFRR sobre impactos ambientais nas bacias hidrograficas urbanas de Boa Vista, RR.

Geosaberes: Revista de Estudos Geoeducacionais, 8(14), p. 85-94, 2017.

SOARES, Jeferson Rosa. $\mathbf{O}$ (não) cumprimento dos Termos de Ajustamento de Conduta e a contribuição da Educação Ambiental em áreas de preservação permanente no município de Palmeira das Missões-RS. (Dissertação de Mestrado). Universidade Federal do Rio Grande, Rio Grande, 121 p.; 2018.

SOARES, Jeferson Rosa., MOTA, Junior Cesar., CORÁ, Marisa Biali., CASTRO, Luis Roberval Bortoluzzi., KITZMANN, Dione lara Silveira. Os recursos hídricos do município de Palmeira das Missões/RS na visão de estudantes do ensino médio. Educação Ambiental em Ação, 65 (1), p. 1-22, 2018.

SOUZA, Marcos José Nogueira de.; OLIVEIRA, Vládia Pinto Vidal de. Análise Ambiental - Uma prática da Interdisciplinaridade no Ensino e na Pesquisa. REDE - Revista Eletrônica do PRODEMA, Fortaleza, v. 7, n. 2, nov. 2011. ISSN 1982-5528. 